\title{
Reflexões sobre a importância do aporte financeiro para a pesquisa científica
}

\section{brasileira com produtos naturais}

\author{
Reflections on the importance of financial support for brazilian scientific research with natural \\ products \\ Reflexiones sobre la importancia del apoyo financiero a la investigación científica brasileña con \\ productos naturales
}

Recebido: 13/04/2021 | Revisado: 20/04/2021 | Aceito: 28/04/2021 | Publicado: 12/05/2021

\author{
Ricardo Botelho Camargo \\ ORCID: https://orcid.org/0000-0003-3960-1068 \\ Universidade Estadual de Maringá, Brasil \\ E-mail: ricardobotelhoc@gmail.com \\ Daniella Londero Silva Batisti \\ ORCID: https://orcid.org/0000- 0003-2371-2644 \\ Universidade Estadual de Maringá, Brasil \\ E-mail: dlbatisti@hotmail.com \\ Viviane Krominski Graça de Souza \\ ORCID: https://orcid.org/0000-0001-7773-932X \\ Universidade Estadual de Maringá, Brasil \\ krominskiviviane@gmail.com \\ Marguit Neumann \\ ORCID: https://orcid.org/0000 -0003-1246-3769 \\ Universidade Estadual de Maringá, Brasil \\ E-mail: marguitn26@gmail.com \\ Cristiane Mengue Feniman Moritz \\ ORCID: https://orcid.org/0000 -0002-9114-2156 \\ Universidade Estadual de Maringá, Brasil \\ E-mail: crisfeniman@yahoo.com.br
}

\begin{abstract}
Resumo
Este trabalho propôs-se à uma reflexão sobre a importância do apoio financeiro para a pesquisa científica brasileira com produtos naturais. Foi realizada uma revisão da literatura com artigos científicos, leis federais, sites das agências de fomento à pesquisa e portais com assuntos relevantes ao tema. A cadeia de produtos naturais é ampla e com destaque para a aplicação de aplicação na indústria de alimentos, de fármacos e cosméticos. Muitos dos modelos industriais ainda trazem obtenção de matéria-prima e processos antagônicos aos modelos sustentáveis, pois entende-se que além dos produtos serem naturais, toda a cadeia deve ser sustentável, considerando as bases do desenvolvimento econômico, social e ambiental. Esse é um reflexo da mudança de mercado como consequência da conscientização dos consumidores e organizações sobre os aspectos de sustentabilidade, trazendo a luz o debate sobre temas como a Agenda 2030, os Objetivos para o Desenvolvimento Sustentável (ODS), o aproveitamento dos recursos naturais, a bioeconomia, sendo todos os assuntos pautados na necessidade de inovação e desenvolvimento. Dessa forma há uma demanda por parte do setor privado em relação a pesquisas aplicada com produtos naturais e para os laboratórios de pesquisas também há oportunidade de obtenção de recursos privados em detrimento aos recursos públicos. Portanto, torna-se fundamental os pesquisadores da linha de pesquisa de produtos naturais conhecerem as opões viáveis de aporte financeiro para darem continuidade às suas linhas de pesquisa, expandir seus grupos de pesquisas e buscarem parcerias com o setor público e privado.
\end{abstract}

Palavras-chave: Sustentabilidade; Produtos naturais; Bioeconomia; Inovação.

\begin{abstract}
This work proposed a reflection on the importance of financial support for Brazilian scientific research with natural products. A literature review was carried out with scientific articles, federal laws, websites for research funding agencies and portals with relevant subjects to the theme. The chain of natural products is wide and the application of the food, pharmaceutical and cosmetics industry stands out. Many of the industrial models still bring raw materials and antagonistic processes to the sustainable models, as it is understood that in addition to the products being natural, the entire chain must be sustainable, considering the bases of economic, social and environmental development. This is a reflection of the market change as a result of the awareness of consumers and organizations about sustainability aspects, bringing to light the debate on topics such as the 2030 Agenda, the Sustainable Development Goals (SDGs), the use of
\end{abstract}


natural resources, the bioeconomy, with all subjects based on the need for innovation and development. Thus, there is a demand on the part of the private sector in relation to applied research with natural products and for research laboratories there is also an opportunity to obtain private resources to the detriment of public resources. Therefore, it is essential for researchers in the natural product research line to know the viable options for financial support to continue their lines of research, expand their research groups and seek partnerships with the public and private sector.

Keywords: Sustainability; Natural products; Bioeconomics; Innovation.

\section{Resumen}

Este trabajo propuso una reflexión sobre la importancia del apoyo financiero a la investigación científica brasileña con productos naturales. Se realizó una revisión de la literatura con artículos científicos, leyes federales, sitios web de agencias financiadoras de investigación y portales con temas relevantes al tema. La cadena de productos naturales es amplia y destaca la aplicación de la industria alimentaria, farmacéutica y cosmética. Muchos de los modelos industriales aún traen materias primas y procesos antagónicos a los modelos sustentables, pues se entiende que además de que los productos sean naturales, toda la cadena debe ser sustentable, considerando las bases del desarrollo económico, social y ambiental. Esto es un reflejo del cambio de mercado producto de la conciencia de consumidores y organizaciones sobre aspectos de sostenibilidad, sacando a la luz el debate sobre temas como la Agenda 2030, los Objetivos de Desarrollo Sostenible (ODS), el uso de los recursos naturales, la bioeconomía, con todos los temas basados en la necesidad de innovación y desarrollo. Así, existe una demanda por parte del sector privado en relación a la investigación aplicada con productos naturales y para los laboratorios de investigación también existe la oportunidad de obtener recursos privados en detrimento de los recursos públicos. Por tanto, es fundamental que los investigadores de la línea de investigación de productos naturales conozcan las opciones viables de apoyo financiero para continuar sus líneas de investigación, ampliar sus grupos de investigación y buscar alianzas con el sector público y privado.

Palabras clave: Sostenibilidad; Productos naturales; Bioeconomía; Innovación.

\section{Introdução}

Parte da dinâmica econômica brasileira é baseada em cadeias de valor voltadas aos produtos naturais. Embora o setor de alimentos tenha destaque nessa cadeia de valor, os produtos naturais são empregados crescentemente nos setores farmacêutico, cosmético têxtil e entre outros. O desempenho das empresas que estão inseridas nessa cadeia de valor está diretamente relacionado à sua capacidade de lançar produtos mais sustentáveis, em constante inovação, além de buscar processos produtivos mais sustentáveis (Instituto de Pesquisa Econômica Aplicada, 2016).

Para Elkington (1998) levar as empresas em direção à sustentabilidade exigirá mudanças dramáticas em seu desempenho em relação ao resultado financeiro. Inicialmente, a agenda de sustentabilidade era visualizada como uma tentativa de harmonizar os resultados financeiros tradicionais com o pensamento emergente sobre a linha de fundo ambiental. No entanto, verificou-se que seria uma transformação complexa. Atualmente, a implantação da sustentabilidade nas empresas é uma ferramenta para alcançar um resultado financeiro triplo, com foco na prosperidade econômica, qualidade ambiental e justiça social. As organizações direcionadas pela sustentabilidade têm como missão a entrega de bens e serviços com preços competitivos, que satisfaçam o consumidor, tragam qualidade de vida e redução progressiva dos impactos ecológicos e sociais.

O caderno de tendências Euromonitor Internacional em sua versão de 2020 (Euromonitor Internacional, 2020) diz que a conscientização ambiental está aumentando na sociedade levando as pessoas à uma cultura de consumo mais sustentável, principalmente nas gerações mais jovens que buscam ter mais experiências de consumo e menos posses. Portanto, novos modelos de negócios que gerem menos resíduos e adotam medidas mais sustentáveis chamaram a atenção desses consumidores mais atentos a essas questões.

O comportamento do mercado mudou significativamente ao longo do tempo, em decorrência principalmente da globalização. A abertura comercial e os acordos bilaterais entre blocos econômicos ou países têm acirrado a concorrência entre as empresas. Portanto, buscar inovações sustentáveis para os seus produtos faz-se necessário para manter a competitividade. Soluções inovadoras e sustentáveis, além da gestão ambiental, qualidade e preço dos produtos, são elementos que podem contribuir na missão de se manter no mercado, como por exemplo a utilização de matérias-primas e produtos naturais em substituição de insumos sintéticos (Pereira, 2011). 
Na busca pelo desenvolvimento sustentável é necessário o investimento em pesquisas científicas que tragam ao setor produtivo alternativas de inovação alinhadas aos Objetivos do Desenvolvimento Sustentável (ODS). Para Muhammad et al. (2020) os produtos naturais têm ampla aplicação nas indústrias farmacêutica, alimentícia, cosmética e aromática. No entanto, os métodos de fabricação atuais de produtos naturais vegetais dependem principalmente da extração de plantas e processamento industrial, que não estão totalmente associados às ações sustentáveis e podem gerar graves problemas ambientais. Desse modo, o investimento em pesquisas com toda a cadeia de valor de produtos naturais, desde a extração até o consumo de produtos utilizando matérias-prima, insumos e processos sustentáveis, em conjunto com a conscientização da indústria sobre as vantagens ambientais e mercadológicas, são fatores que contribuem para uma sociedade mais sustentável.

A pesquisa científica desenvolvida nas universidades brasileiras depende de infraestrutura compatível para alcançar seus objetivos, o que pode exigir elevado aporte financeiro. Apesar das receitas das universidades virem de fontes distintas, privadas ou públicas, ainda há motivos de preocupação da comunidade acadêmica para equilibrar receitas e despesas (Riscarolli; Rodrigues \& Almeida, 2010). Andreassi (2005) diz que a infraestrutura é fundamental para o ambiente de inovação, pesquisa e desenvolvimento e que uma alternativa ao investimento público são as Parcerias Público Privado (PPP).

Empresas que atuam na cadeia produtiva de produtos naturais podem inovar buscando parcerias com as universidades públicas para desenvolverem seus produtos e otimizar seus processos, utilizando a Lei federal no $11.196 / 2005$, conhecida como "Lei do Bem". Essa lei é um exemplo de estímulo à PPP, pois trata-se de incentivo fiscal para empresas que investem em inovação, pesquisa e desenvolvimento (Lopes \& Beuren, 2016).

Neste trabalho utilizou-se a ferramenta de revisão da literatura em três bases de busca online: Portal de Periódicos CAPES, Scielo e Science Direct, com artigos selecionados publicados entre 2002 e 2020. Também se utilizou fontes governamentais (leis e site das agências federais de fomento à pesquisa), assim como acesso aos portais para que trazem notícias/informações relativos ao tema. Este trabalho propôs-se à uma reflexão sobre a importância do apoio financeiro para a pesquisa científica brasileira com produtos naturais.

\section{Metodologia}

Esse estudo foi realizado por meio de uma pesquisa bibliográfica com abordagem qualitativa, de acordo com Pereira at al. (2018, p. 67) "Os métodos qualitativos são aqueles nos quais é importante a interpretação por parte do pesquisador com suas opiniões sobre o fenômeno em estudo". Foram utilizadas as bases: CAPES, Scielo e Science Direct, também foi realizado pesquisas nos sites da FINEP e CNPQ, foram encontrados artigos nos idiomas português, espanhol e inglês. Também foram realizadas pesquisas em sites oficiais brasileiros para buscar leis e decretos que pudessem contribuir para a construção deste trabalho.

\section{Cadeia de Valor de Produtos Naturais e Inovação}

As riquezas naturais do Brasil colocam o país em posição de destaque na competição geopolítica e econômica com outras nações. É relevante dar devida importância para pesquisas sobre a cadeia de valor de produtos naturais, pois esses estudos podem auxiliar empresas brasileiras a melhorarem sua produtividade nessa cadeia e se tornarem mais sustentáveis. Estima-se que dois terços das exportações brasileiras vêm de produtos naturais, sendo que grande parte desse montante é exportado como commodities. Portanto, pesquisas que auxiliam a cadeia de valor de produtos naturais a ser mais inovadora é uma forma para agregar valor nas exportações e tornar o país mais sustentável (Instituto de Pesquisa Econômica Aplicada, 2016).

As tendências de mercado estão levando organizações à buscarem alternativas sustentáveis para seus produtos e serviços. O debate sobre bioeconomia vem ganhando espaço na agenda de governos, organizações do terceiro setor, academias e organizações privadas, para alinhar desenvolvimento econômico com proteção do meio ambiente e gerar renda e qualidade de 
vida para a sociedade. O estudo em bioeconomia faz-se necessário por oportunizar o desenvolvimento sustentável, o que geralmente não é obtido por meio dos modelos tradicionais de desenvolvimento econômico (Willerding, et al. 2020).

O financiamento da pesquisa científica é um importe fator para os avanços tecnológicos, econômicos e sociais de um país. Com o advento da globalização, a partir da década de 90, a inovação aliada com ciência e tecnologia passou a ter um papel relevante na competitividade da macroeconomia. No decorrer dos anos que se seguiram, determinadas organizações governamentais planejaram estratégias para aumentar a maturidade e a qualidade da pesquisa científica desenvolvida nas instituições de ensino superior, por ser ainda a principal fonte de fornecimento de conhecimento (Francisco \& Zucatto, 2018).

Para Ventura et al. (2020) é fundamental o fomento da pesquisa de forma contínua e sistemática. Muitos governantes e gestores empresariais buscam na ciência respostas rápidas aos seus desafios cotidianos, porém para a resolução de problemas, a evolução dos processos e a inovação é necessário o investimento em pesquisas interdisciplinares. Aumentando o investimento em pesquisa, inovação e desenvolvimento, é possível construir polos tecnológicos que busquem a resolução de problemas sociais e consigam auxiliar determinada sociedade no seu crescimento econômico, social e ambiental.

Em um mundo de constantes mudanças, onde a sociedade está vivenciando uma era do conhecimento, o desenvolvimento é impulsionado pela ciência, tecnologia e inovação. É possível ver essas transformações nos mais diversos sistemas sociais, na política, na educação e na economia, onde talentos pautam processos e a competição econômica entre países é somada pela corrida científica, fazendo com que a universidade assuma um papel central para a promoção da inovação. Nesse contexto o termo inovação ganha nova roupagem e extrapola a barreira de ser apenas algo que transforma conhecimento em valor econômico. Com uma nova significação, a inovação é aquilo capaz de gerar soluções para adversidades econômicas, sociais e políticas, com ganhos para todos os atores da sociedade, seja público, privado ou do terceiro setor (Neves \& Neves, 2011).

No Brasil, determinadas regiões desenvolveram-se de forma tardia na sua industrialização, no seu sistema financeiro e em suas instituições de pesquisa. Esses importantes componentes auxiliam na compreensão dos atuais limites dos sistemas de inovação. Nesse contexto, é possível observar que a interação da universidade e o setor de pesquisa científica em alinhamento com o setor privado ocorre de forma esporádica e concentrada em alguns pontos ou regiões do país, além de serem priorizadas determinadas áreas do conhecimento que estão alinhadas com os segmentos específicos da atividade econômica regional (Spínola; Lima \& Fernandes, 2015).

\subsection{Produtos naturais na bioeconomia}

A atividade humana intensiva e os modelos de desenvolvimento convencionais, baseados em combustíveis fósseis, vêm ocasionando graves impactos ambientais em todo o mundo. Devido a isso, o planeta enfrenta uma série de grandes desafios ambientais, econômicos e sociais, que devem ser atendidos para enfrentar as mudanças climáticas, a vulnerabilidade de algumas regiões, a redução da biodiversidade, a segurança alimentar e nutricional, a poluição da água e do solo, as desigualdades sociais e a garantia de bem-estar para todos. Para atender essas questões, o conceito de bioeconomia está se consolidado e se promove como modelo alternativo para o desenvolvimento sustentável e o crescimento da economia verde. A América Latina tem extraordinária riqueza em sua biodiversidade e isso garante grande capacidade de produção de biomassa, oferece um enorme potencial para a produção e transformação de produtos e representa uma conjuntura estratégica para promover a diversificação produtiva agrícola e agroindustrial. Para isso é necessário potencializar a capacidade cientifica em biotecnologia e na cadeia de valor de produtos naturais, pois essa é capaz de auxiliar desde a produção primária sustentável até a industrialização de produtos que estejam em acordo com as demandas por produtos mais sustentáveis (Jaramillo, 2018).

Um dos princípios da economia verde é desenvolver propostas sobre políticas consideradas relevantes para alcançar o desenvolvimento sustentável. Uma economia verde é aquela que gera baixas emissões de carbono, faz uso dos recursos de forma 
eficiente e é inclusiva socialmente. Esse crescimento tem como pilar a inovação como meio para consolidar o desenvolvimento sustentável e gerar novas oportunidades econômicas e novos mercados (Reinoso, 2016).

A bioeconomia surge como um conceito que pode levar desenvolvimento sustentável as regiões de proteção ambiental, propondo para as pessoas que estão inseridas em determinados biomas, que gerem renda para si e também sejam motivadas à contribuírem para a preservação do ambiente onde vivem, criando um ciclo virtuoso onde as gerações futuras serão impactadas positivamente das ações atuais (Willerding, et al. 2020).

\subsection{Agenda 2030}

O debate mundial sobre desenvolvimento sustentável ganhou espaço na agenda das Nações Unidas em 1972 na cidade de Estocolmo na Suécia onde foi realizada a primeira conferência sobre o meio ambiente. Posteriormente, outras conferências foram realizadas, a Eco-92 no Rio de Janeiro, a Rio+10 e a Rio+20, todas elas tiveram o intuito de propor ações que contribuíssem para um mundo mais sustentável. Em 2015 a ONU em parceria com governos, entidades não governamentais e pesquisadores elaboraram a Agenda 2030. Nessa Agenda consta os 17 Objetivos para o Desenvolvimento Sustentável (ODS), que vão além da proteção ambiental e climática e traça objetivos e metas com o intuito de promover a paz, prosperidade e justiça social (Organizações das Nações Unidas, 2020).

Historicamente as empresas são grandes responsável por afetarem o meio ambiente e, dependendo de suas atividades, isso ocorre em grande ou pequena escala. Dessa forma, ao analisar os fatos históricos ligados à Responsabilidade Social Corporativa (RSC), fica evidente que cabe às organizações empresariais desenvolverem formas de explicarem suas ações para a sociedade e seus stakeholders. Observa-se na Figura 1 que a preocupação com as informações de RSC reportadas pelas organizações vem desde a década de 50 e culminou com os ODS em 2015. Embora as ODS seja uma agenda para 2030, é relevante ressaltar que a projeção da população para 2050 é de 9,6 bilhões de pessoas e isso pode levar ao aumento da geração de resíduos. Dessa forma, são necessárias empresas cada vez mais conscientes e transparentes no que diz respeito à RSC.

Figura 1. Linha do tempo da Responsabilidade Social Corporativa (RSC).

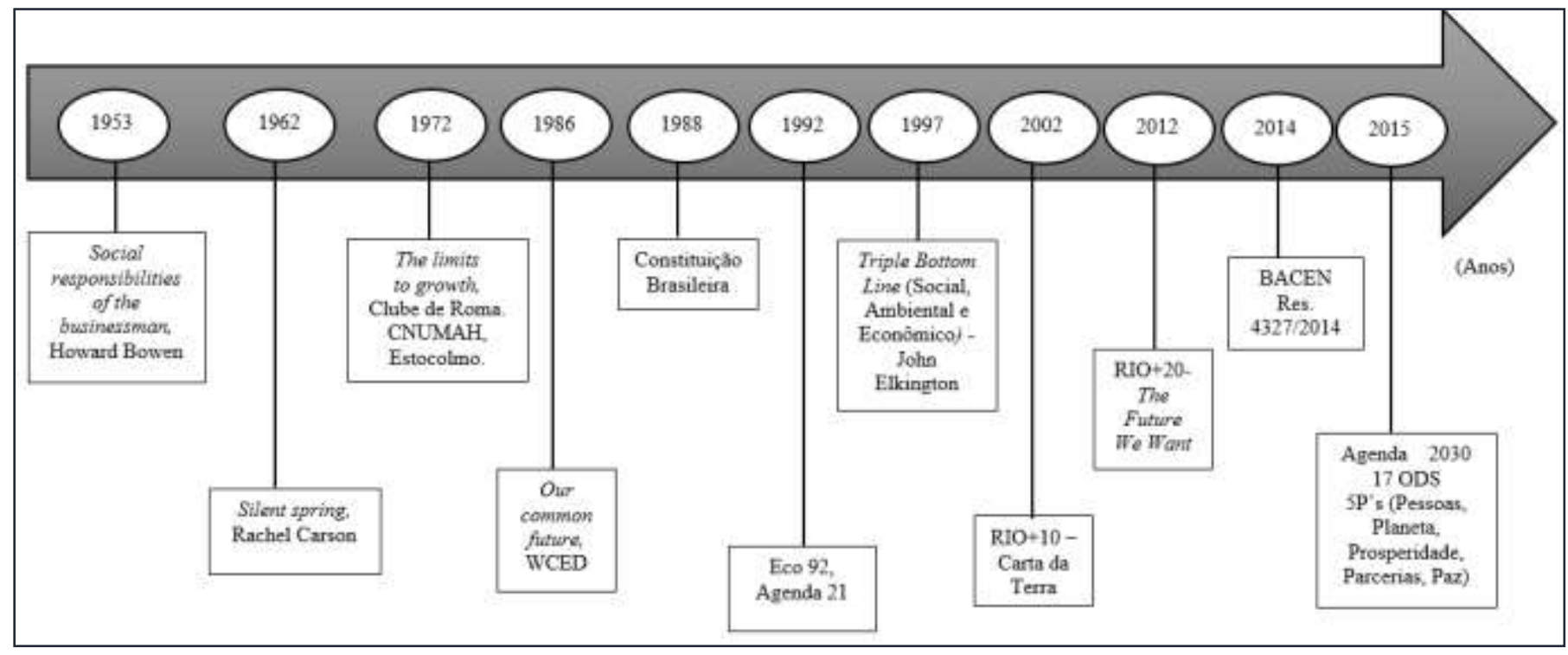

Fonte: Almeida, Neumann e Raimundini (2018). 
Para Sartori et al. (2014) o tema sustentabilidade foi definido ao longo do tempo, tomando como base a desigualdade social, os problemas ambientais e as crises econômicas. Pela sua complexidade conceitual e contínua, surgiram abordagens diferentes que buscam explicar o que é sustentabilidade. Para esses autores a sustentabilidade é caracterizada como:

[...] um princípio aplicável à sistemas. Sistemas abertos, para interagir com a sociedade-natureza, envolvendo sistemas industriais (transporte, produção, energia, etc.), os sistemas sociais (urbanização, mobilidade, comunicação, etc.) e sistemas naturais (solo, atmosfera, sistemas aquáticos e bióticos, etc.), incluindo os fluxos de informações, bens, materiais, resíduos. Isto é, a sustentabilidade envolve uma interação com sistemas dinâmicos que estão em constante mudança e necessitam de medidas proativas.

Ruano (2017) destacou que o alcance de conhecimentos e aptidões requer uma combinação entre escola e desenvolvimento sustentável, independente de país, cultura ou credo, ressaltando que os ODSs representam uma alteração no curso da civilização, transformando hábitos individuais e coletivos, além da forma como o meio ambiente é explorado.

\subsection{Inovação}

Em países desenvolvidos a inovação está sendo alcançada através de pesquisas realizadas em micro e pequena empresa. O estímulo criado pelo processo de inovação traz para as pequenas empresas oportunidades de acordo com as demandas do mercado. Nos Estado Unidos é lei que todas as agências e organismos de fomento à pesquisa, destinem parte de seus investimentos em projetos que busquem a inovação tecnológica, gerando valor comercial nas pequenas empresas. No Brasil, parte do conhecimento produzido ainda fica confinado no ambiente acadêmico, provocando um gargalo no desenvolvimento científico e tecnológico do país, tendo como consequência o distanciamento de muitos grupos de pesquisas dos parques empresariais que fomentam a pesquisa, inovação e desenvolvimento (Perez, 2002).

Para Quintal e Terra (2014) nações desenvolvidas e em desenvolvimento vêm buscando aumentar a concentração de parques tecnológicos. Essas ferramentas contribuem para a dinâmica das economias através de agregação de conhecimento e suas estruturas têm a função de transformar conhecimento em riquezas. Dessa forma, é natural que esses parques estejam situados próximos das universidades e centros de pesquisas, tornando os países mais competitivos internacionalmente, promovendo empregos qualificados, maior recolhimento de impostos e o bem-estar social.

Para Barbosa et al. (2017), na década de 90 o Brasil passou por grandes transformações políticas e econômicas. As pequenas empresas passaram a ter um papel relevante na economia e também o foco na inovação e na sustentabilidade passou a fazer parte do escopo do desenvolvimento. Portanto, foram desenvolvidas políticas públicas para o desenvolvimento inovador e sustentável, mas muitas políticas não alcançaram para às micros e pequenas empresas (MPEs). Nesse caso, as incubadoras passaram a ter relevância crucial para que MPEs consigam o desenvolvimento tecnológico e a inovação para os seus produtos e serviços. O Estado tem papel fundamental na coordenação de políticas públicas para o estímulo de ações, diretrizes e a busca da melhoria no relacionamento entre os atores da sociedade. A universidade participa desse processo como um importante agente de política pública que promove o desenvolvimento sustentável, pois são fontes de conhecimento e têm a expertise em pesquisa científica nas mais diversas áreas.

No Brasil, determinadas regiões desenvolveram-se de forma tardia na sua industrialização, no seu sistema financeiro e em suas instituições de pesquisa. Esses importantes componentes auxiliam na compreensão dos atuais limites dos sistemas de inovação. Nesse contexto, é possível observar que a interação da universidade e o setor de pesquisa científica em alinhamento com o setor privado ocorre de forma esporádica e concentrada em alguns pontos ou regiões do país, além de serem priorizadas determinadas áreas do conhecimento que estão alinhadas com os segmentos específicos da atividade econômica regional (Spínola; Lima \& Fernandes, 2015). 
Para o mercado a inovação tem a função de gerar valor econômico por meio do conhecimento. É essencial que haja uma comunicação mais aberta e clara entre as instituições de ensino e pesquisa e o setor privado e isso se faz necessário para que ocorra a transferência do conhecimento de pesquisa aplicada. Porém, deve-se quebrar paradigmas, o setor público e privado conversarem para unir forças e buscarem inovação por meio de cooperação. Também é necessário que haja maior segurança jurídica para tanto. A inovação para o mercado é algo que gera produtos e serviços que podem alavancar lucros e melhorar a competitividade. Em contrapartida muitos projetos de inovação ficam confinados nas academias, devido à dificuldade de entendimento entre esses dois setores (Neves \& Neves, 2011).

A Lei de Inovação Tecnológica - LIT (Lei Federal n. ${ }^{\circ} 10.973$ de 02 de dezembro 2004) estabelece medidas para o incentivo à inovação, pesquisa científica e tecnológica para o setor produtivo. Essa lei representa um grande avanço para as políticas industriais e tecnológicas do Brasil. Essa lei exige que ocorra intensiva interação entre o setor público, setor privado e a comunidade acadêmica, facilitando o surgimento de uma cultura de inovação no país (Pereira \& Kruglianskas, 2005).

No que tange ao processo de pesquisa, é pertinente frisar que os pesquisadores são peças-chave na resolução de questões sociais urgentes, pois estão em constante busca de soluções de problemas. Destaca-se a responsabilidade social e ética que deve partir do pesquisador em exigir condições adequadas para a realização das pesquisas, mantendo um perfil de independência face as pressões que pode sofrer para desviar-lhe de sua responsabilidade ético-social (Lima \& Bavaresco, 2016).

De acordo com Andreassi (2005), para atingir um patamar mais elevado de maturidade social, a sociedade cobra que o governo brasileiro estabeleça programas e políticas de apoio à inovação tecnológica. Contudo, esperar somente que o governo faça algo não surtirá os resultados esperados. Empresas precisam repensar o seu papel na sociedade e sobre sua, precisam melhorar seus processos, tornarem-se mais inovadoras e competitivas.

\subsection{Financiamento público para a pesquisa científica}

Para Neves e Neves (2011) as pesquisas científicas desenvolvidas no Brasil provêm principalmente das universidades públicas. O financiamento das pesquisas científicas, em grande parte, é destinado a bolsas de estudo e para o apoio aos grupos de pesquisas. Geralmente os editais são direcionados para atividades consideradas estratégicas. As principais agências brasileiras de fomento à pesquisa são: a Financiadora de Estudos e Projetos (FINEP), o Conselho Nacional de Desenvolvimento Científico e Tecnológico (CNPq) e a Coordenação de Aperfeiçoamento de Pessoal de Nível Superior (CAPES). Essas agências divulgam editais regularmente para apoiar grupos de pesquisas e pesquisadores, como para a formação de redes de pesquisas nacionais ou internacionais. Há uma grande competição pelos recursos e isso se dá muitas vezes pela escassez dos mesmos.

O CNPQ foi criado pela Lei n. 1.310, de 15 de janeiro de 1951 e desde então tem atuação essencial na condução de políticas públicas de pesquisa científica. Está vinculado ao Ministério da Ciência, Tecnologia, Inovações e Comunicações, sendo uma fundação pública e tem em suas atribuições o fomento à pesquisa científica, tecnológica e de inovação, promovendo a formação de pessoas qualificadas para atuarem em pesquisas científicas nas mais diversas áreas do conhecimento. Tem como missão "Fomentar a Ciência, Tecnologia e Inovação e atuar na formulação, execução, acompanhamento, avaliação e difusão de suas políticas, contribuindo para o avanço das fronteiras do conhecimento, o desenvolvimento sustentável e a soberania nacional". Sua visão é "Ser uma instituição de reconhecida excelência na promoção da Ciência, da Tecnologia e da Inovação como elementos centrais do pleno desenvolvimento da nação brasileira" (Conselho Nacional De Desenvolvimento Científico E Tecnológico, 2020).

Criado em 1967 pelo decreto de Lei federal n 61.056, de 24 de julho de 1967, o FINEP atua na cadeia de inovação com ações estratégicas, focando no desenvolvimento sustentável do país. Tem como missão "Promover o desenvolvimento econômico e social do Brasil por meio do fomento público à Ciência, Tecnologia e Inovação em empresas, universidades, institutos tecnológicos e outras instituições públicas ou privadas" e como visão "Transformar o Brasil por meio da inovação", 
pautado por valores como "visão estratégica, compromisso público, excelência na gestão, valorização do seu capital humano e atitude inovadora (Financiadora De Estudos E Projetos, 2020).

A partir de uma campanha nacional para aperfeiçoar os recursos humanos com nível de ensino superior no Brasil, em 1951 o governo Vargas criou pelo Decreto n. 29.741 de 11 de julho de 1951 a Coordenação de Aperfeiçoamento de Pessoal de Nível Superior (CAPES). Esse órgão governamental tem como missão principal a coordenação e expansão de curso de pósgraduação stricto sensu, em todo o território brasileiro. Também atua na formação de professores da educação básica, qualificando pessoas no Brasil e no exterior. Suas principais atividades são: avaliação de pós-graduação stricto sensu, acesso e divulgação de produção científica, investimento na formação de recursos humanos de alto nível, no país e exterior, promoção da cooperação científica internacional, indução e fomento da formação inicial e continuada de professores para a educação básica nos formatos presencial e a distância (Coordenação De Aperfeiçoamento De Pessoal De Nível Superior, 2020).

As atividades científicas e tecnológicas desenvolvidas no Brasil estão registradas nos diretórios das agências de fomento brasileiras. Esses diretórios são ambientes para a alocação de pesquisas e serve como base de colaboração com a comunidade científica e para a produção do conhecimento. A sociedade está cada vez mais interessada em conhecer os resultados obtidos pela comunidade acadêmica. Portanto, justifica-se as agências de fomento e as instituições de ensino investirem na realização de pesquisas coletivas para dar maior visibilidade de suas atuações para a sociedade (Perucchi \& Garcia, 2011).

\subsection{Parcerias público-privado para a pesquisa científica}

Para Balduino (2020) as PPP ganharam força no Brasil a partir do Plano Diretor da Reforma do Aparelho do Estado (PDRAE) em 1995, induzindo o aumento dessas parcerias e levando o setor privado a influenciar a criação de políticas públicas. O PDRAE apresentou quais seriam as reformas estruturantes para superar a crise econômica naquele momento. O documento apresentou três estratégias para a superação da crise: a terceirização, privatizações e as PPPs, intituladas de "quase mercado", pois apesar das propriedades continuarem sendo públicas, a gestão passou para o setor privado.

A Lei N ${ }^{\circ} 11.079$, de 30 de dezembro de 2004, "Institui normas gerais para licitação e contratação de parceria públicoprivada no âmbito da administração pública" e a Lei No 13.529, de 4 de dezembro de 2017, "Dispõe sobre a participação da União em fundo de apoio à estruturação e ao desenvolvimento de projetos de concessões e parcerias público-privadas". As PPPs surgiram para dar ao Estado condições de executar projetos com recursos privados. Elas podem ocorrer quando o governo desembolsa o dinheiro e o setor privado realiza os serviços contratados, ou quando o setor público custeia parte do projeto e o usuário outra. As PPPs geralmente são utilizadas em projeto de infraestruturas, alguns exemplos são obras de saneamento, construção de prédios públicos e rodovias. O valor mínimo para um contrato de parceria público privado é de a R \$10.000.000,00 (dez milhões de reais), e o tempo da parceria deverá ser entre 5 e 35 anos (Brasil, 2020).

As PPPs são transações em que o setor público faz pagamentos ao setor privado mediante a execução de projetos. Geralmente a iniciativa privada não teria interesse em empreender nos projetos que são executados mediante PPPs, pois esses não trariam retorno financeiro esperado. No entanto, traz retorno social e justifica o interesse do poder público em investir nesses empreendimentos (Pereira \& Ferreira, 2008).

Considerando os desafios do Estado para aumentar os investimentos em pesquisa, inovação e tecnologia, o setor privado é uma alternativa para viabilizar tais investimentos. No entanto, para ocorrer a Parceria Público Privado (PPP) é importante avançar na quebra de paradigmas e diminuir a distância que há entre os dois setores, buscando um modelo contemporâneo de reciprocidade e sinergismo (Galvão \& Oliveira, 2014).

Entre os incentivos para inovação no Brasil, destaca-se a Lei n. 11.196/2005, publicada em 21 de novembro de 2005, conhecida como "Lei do Bem". Essa lei tem como base o incentivo tributário para aumentar o desenvolvimento de inovação em produtos, serviços e processos. De acordo essa lei federal, uma empresa que fizer investimentos em inovação poderá deduzir de 
20,4\% até 34\% no Imposto de Renda de Pessoa Jurídica (IRPJ) e na Contribuição Social sobre o Lucro Líquido (CSLL). Também terá a possibilidade de reduzir 50\% do Imposto sobre Produtos Industrializados (IPI) na compra de máquinas e equipamentos destinados a pesquisas inovação e desenvolvimento (Brasil, 2005).

No entanto, para Fabiani e Sbragia (2014) a Lei do Bem tem a necessidade de evoluir para que haja a democratização desse benefício. Apesar do número de empresas que buscaram os benefícios terem aumentado ao longo dos anos, é importante uma revisão nessa lei, pois hoje ela contempla apenas empresas que estejam no regime tributário de lucro real, sendo que grande parcela das empresas nacionais estão enquadradas nos regimes do simples nacional ou no lucro presumido.

\section{Considerações Finais}

No Brasil, os aportes federais estatais para a pesquisa científica são advindos das agências de fomento CAPES, FINEP e CNPQ. Há também outros mecanismos que podem auxiliar e influenciar na ampliação de estudos e dos grupos de pesquisas com produtos naturais, como as leis de incentivos a inovação, a possiblidade de PPP e organizações empresariais que estão investindo em $P \& D$ de produtos naturais, para atender uma exigência crescente do mercado global.

Temas como sustentabilidade, agenda 2030 e bioeconomia estão sendo debatidos em grande parte do mundo. Países precisam cumprir as metas relacionadas aos ODS e tornarem-se mais sustentáveis. Assim a bioeconomia vem ganhando espaço no debate de governos e organizações para auxiliar nos desafios do desenvolvimento sustentável.

Contudo, se faz necessária maior sinergia entre os pilares da triple hélice da inovação, aproximando a academia do setor privado, com políticas públicas governamentais de incentivo à inovação, ciência e tecnologia. Essa interação possibilitará o surgimento de produtos naturais originados de uma cadeia sustentável e que atendam as demandas de mercado.

\section{Referências}

Almeida, R. G., Neumann, \& M., Raimundini, S. L. (2018). O que é evidenciado no Brasil sobre a Responsabilidade Social Corporativa advinda da Política Nacional de Resíduos Sólidos (PNRS) nos Formulários de Referência e Relatos Integrados. Sociedade, Contabilidade e Gestão (UFRJ), 13(1), 1-25.

Andreassi, T. (2005). Ações internas voltadas ao fomento da inovação: as empresas também devem fazer sua "lição de casa". Caderno EBAPE.BR, edição especial, 1-10.

Balduino, M. A. C. (2020). Programa Jovem de Futuro: uma tecnologia educacional do terceiro setor. Revista Interações (UCDB), $21(2), 233-243$.

Barboza, R. A. B. Fonseca, S. A., \& Ramalheiro, G. C. F. (2017) Papel das políticas públicas para potencializar a inovação em pequenas empresas de base tradicional. REGE - Revista de Gestão, 24(1), 58-71, 2017.

Brasil (2021). Lei $\mathrm{n}^{\circ} 11.079$, de 30 de dezembro de 2004 institui normas gerais para licitação e contratação de parceria público-privada no âmbito da administração pública. http://www.planalto.gov.br/ccivil_03/_ato2004-2006/2004/lei/111079

Brasil (2021). Lei $n^{\circ}$ 11.196/2005, de 21 de novembro de 2005. Institui o regime especial de tributação para a plataforma de exportação de serviços de tecnologia da informação - REPES, o regime especial de aquisição de bens de capital para empresas exportadoras - RECAP e o programa de inclusão digital, dispõe sobre incentivos fiscais para a inovação tecnológica. https://legislacao.presidencia.gov.br/atos/?tipo=LEI\&numero=11196\&ano=2005\&ato=eddc3YU5EMRpWT7e9

Brasil (2021). Lei n ${ }^{\circ} 13.529$, de 4 de dezembro de 2017 dispõe sobre a participação da União em fundo de apoio à estruturação e ao desenvolvimento de projetos de concessões e parcerias público-privadas, altera a Lei n 11.079 , de 30 de dezembro de 2004, que institui normas gerais para licitação e contratação de parceria público-privada na administração pública, a Lei n ${ }^{\circ} 11.578$, de 26 de novembro de 2007, que dispõe sobre a transferência obrigatória de recursos financeiros para a execução pelos Estados, Distrito Federal e Municípios de ações do Programa de Aceleração do Crescimento (PAC), e a Lei n 12.712 , de 30 de agosto de 2012, que autoriza o Poder Executivo a criar a Agência Brasileira Gestora de Fundos Garantidores e Garantias S.A. (ABGF). http://www.planalto.gov.br/ccivil_03/_Ato2015-2018/2017/Lei/L13529.htm\#art6

Conselho Nacional de Desenvolvimento Científico (CNPQ) (2020). Institucional. http://www.cnpq.br/web/guest/apresentacao_institucional

Coordenação de Aperfeiçoamento de Pessoal de Nível Superior (CAPES). Institucional. https://www.gov.br/capes/pt-br/acesso-a-informacao/institucional

Elkington, J. (1998). Cannibals with forks. Orange County: Century Business.

Euromonitor Internacional (2020). 10 Tendências Globais de Consumo. https://go.euromonitor.com/white-paper-EC-2020-Top-10-Global-Consumer-TrendsPG.html

Fabiani, F., \& Sbragia, R. (2014). Tax incentives for technological business innovation in Brazil: The Use of the good law - lei do bem (Law no. 11196/2005). Journal of Technology Management \& Innovation, 4(9), 53-63. 
Financiadora de Estudos e Projetos (FINEP) (2020). Sobre a FINEP. http://www.finep.gov.br/a-finep-externo/sobre-a-finep

Francisco, N. A., \& Zucatto, L. C. Estado da arte da produção acadêmica relacionada ao financiamento e fomento da pesquisa científica no brasil: uma análise a partir do ciclo de políticas públicas. Revista Práticas de Administração Pública, 2(1), 41-62.

Galvão, C. B., \& Oliveira, J. P. A. (2014). Parcerias público-privadas: contributo para a análise do seu contexto de incidência. Lex Humana, 6 (1), 29-43.

Instituto de Pesquisa Econômica Aplicada (2020). Cadeias de valor baseadas em recursos naturais: o caso do Brasil. http://repositorio.ipea.gov.br/bitstream/11058/6589/1/td_2173.pdf

Lopes, I. F., Beuren, I. M. (2016). Evidenciação da inovação no relatório da administração: uma análise na perspectiva da lei do bem (lei nº 11.196/2005). Perspectivas em Gestão \& Conhecimento, 6(1), 109-127.

Muhammad, A., Feng, X., Rasool, A., \& Sun, W., LI, C. (2020). Production of plant natural products through engineered Yarrowia lipolytica. Biotechnology Advances, 43 (107555), 1-14.

Neves, C. E. B., \& Neves, F. N. (2011). Pesquisa e Inovação: novos desafios para a educação superior no Brasil e na Alemanha. Caderno CRH, 24(63), 481501.

Organização das Nações Unidas No Brasil (ONUBR) (2020). Como as nações unidas apoiam o desenvolvimento sustentável no Brasil. https://nacoesunidas.org/pos2015/ods2/

Paiva, F. C. S., \& Giesta, L. C. (2019). Gestão socioambiental em micro e pequenas indústrias de Pau dos Ferros-RN. Revista Gestão e Produção, $26(2), 1-17$.

Pereira, A. S., Shitsuka, D. M., Parreira, F. J., \& Shitsuka, R. (2018). Metodologia da pesquisa científica. UFSM. https://repositorio. ufsm. br/bitstream/handle/1/15824/Lic_Computacao_Metodologia-Pesquisa-Cientifica. pdf.

Pereira, J. (2011) Gestão ambiental do produto Rumo à sustentabilidade industrial Revista Portuguesa e Brasileira de Gestão. 10(1-2), 13-23.

Pereira, J. M., \& Kruglianskas, I. (2005). Gestão de inovação: a lei de inovação tecnológica como ferramenta de apoio às políticas industrial e tecnológica do Brasil, Rae Eletrônica, 4(2), 01-21.

Pereira, R. A. C., \& Ferreira, P. C. (2008). Efeitos de Crescimento e Bem-estar da Lei de Parceria Público-Privada no Brasil. Revista Brasileira de Educação, 62(2), 207-219.

Perez, J. F. (2002). Pesquisa a construção de novos paradigmas. Revista São Paulo em Perspectiva, 16(4), 30-35.

Perucchi, V, \& Garcia, J. C. R. (2011). Projetos de pesquisa dos grupos do Instituto Federal de Educação, Ciência e Tecnologia da Paraíba. Revista Perspectivas em Ciência da Informação, 16(3), 131-147.

Quintal, R. S., Terra, B. R. C. S. S. R. (2014). Políticas organizacionais de ciência, tecnologia e inovação e gestão da propriedade industrial: uma análise comparativa em Instituições de Pesquisa. Gestão e Produção, 21(4), 760-780.

Riscarolli, V., Rodrigues, L. C., \& Almeida, M. I. R. (2010). Contribuições ao processo de captação de recursos para unidades de instituições de ensino superior no Brasil. Revista de Ciências da Administração, 12(27), 11-41.

Ruano, J. C. (2016). O desenvolvimento sustentável na educação superior. Propostas biomiméticas e transdisciplinares. Revista Iberoamericana de Educación, $73,203-224$.

Sartori, S. Latronico, F., \& Campos, L. M. S. (2014). Sustentabilidade e desenvolvimento sustentável: uma taxonomia no campo da literatura. Revista Ambiente \& Sociedade, 17(1), 1-22.

Spínola, F. D., Lima, J. P. R., \& Fernandes, A. C. (2015). Interação Universidade-Empresa: o caso do setor sucroalcooleiro de Pernambuco. Revista Economia e Sociedade, 1(24), 121-149.

Ventura, D. F. L., Ribeiro, H., Giulio, G. M., Jaime, P. C., Nunes, J., Bógus, C. M. Antunes, J. L. F., \& Waldman, E. A. (2020). Desafios da pandemia de COVID-19: por uma agenda brasileira de pesquisa em saúde global e sustentabilidade. Caderno de Saúde Pública, 36(4), 1-5.

Willerding, A. L., Silva, L. R., Silva, R. P., Assis, G. M. O., \& Paula, E. V. C. M. (2020) Estratégias para o desenvolvimento da bioeconomia no estado do Amazonas. Revista Estudos Avançados, 34(98), 143-165. 